\title{
Special Education Teachers' Perception on Teaching Transition Skills for Students with Intellectual Disabilities
}

\author{
Yungkeun Park \\ Dept. of Special Education, Sehan University, Korea \\ a5890@naver.com
}

\begin{abstract}
The purpose of this study was to investigate the current perceptions of special education teachers about the transition skills of students with intellectual disabilities (ID) for the successful transition into adult life. The results of this study are as follows. First, overall special education teachers for students with ID perceived the importance of teaching ten transition skills areas in order to help students with ID have a successful transition to adult life. Second, although, special education teachers for students with ID perceived the importance of teaching ten transitions, the teachers perceived their implementation level of these skills as relatively low. Through importance-performance analysis (IPA) of 10 transition skills by using the mean difference between the perception of importance and performance of teachers, 4 areas such as concentrate here, keep up the good work, low priority, possible overkill are suggested. There are some suggestions based on the results of the research.
\end{abstract}

Keywords: Transition skills, Students, Intellectual disabilities, Teacher perception

\section{Introduction}

Today, special education is aimed at the practical community inclusion of students with special educational support needs. The practical community inclusion refers to the integration that allows students to live as a member of society in the community through employment, even after they have graduated from school, beyond integration in the school-aged school environment [1].

Thus, most special education teachers and parents of students with disabilities focus on preparing to live as an independent adult after graduating from high school and a productive member of the community. Therefore, special education teachers should provide a curriculum that focuses on preparing students to live an adult life, such as the participation in community, participation in leisure and hobbies, admission to higher education, and employment after they become adults [2].

Because students with intellectual disabilities have limitation in the conceptual, practical and social adaptation skills, as well as intellectual deficiencies, compared to their age, the school curriculum is designed to enable them to acquire transition skills through appropriate transition education tailored to their individualized special needs [3].

Although students with intellectual disabilities have received special education through three years of junior high school, three years of high school, and two years of postsecondary

Article history:

Received (October 5, 2019), Review Result (November 21, 2019), Accepted (December 28, 2019) 
education, they have not achieved the successful transition outcome. Although there is a growing awareness of importance about transition skills through transition education in the field of special education, the practical implementation of transition service is relatively low [4].

The purpose of this study was to investigate the level of awareness about the importance level and the performance level of special education teachers on transition skills that students with intellectual disabilities should learn so that they can have successful transition into adult life. Through this, this study is to provide basic information to enhance the importance and performance of transition skills needed in the field so that students with intellectual disabilities can have successful transition into adult life.

\section{Study method}

\subsection{Participant}

The purpose of this study was to investigate the perception of special teachers on the transition skills of students with intellectual disabilities, the subjects of this study were secondary special education teachers in special schools and special classes nationwide. In order to select the subjects of this study, 200 questionnaires were distributed and 149 questionnaires were collected with the cooperation of special education school teachers and special class teachers in secondary schools nationwide. A total of 144 questionnaires were analyzed, excluding 5 questionnaires that were not completed properly.

\subsection{Survey questionnaire}

In order to examine the teachers' perceived importance and performance of teaching students with intellectual disabilities on the transition skills required for a successful transition to adult life, the researcher used questionnaire developed by Sitlington et al. [5]. Chronbach's alpha coefficients were calculated to investigate the internal consistency of each questionnaire item.

\subsection{Data analysis}

Statistical analyses were performed using SPSS 21.0. An independent t-test was conducted to compare the perceived importance and performance and then investigate the transition skills that need to be taught for adolescents with intellectual disabilities.

An independent t-test and IPA analysis was conducted to compare the perceived importance and actual performance and then investigate the transition skills that need to be taught for adolescents with intellectual disabilities [6][7].

\section{Results}

\subsection{Teachers' perceived importance and performance of teaching transition skills for with intellectual disabilities}

The teachers' perceived importance and performance of teaching transition skills for students with intellectual disabilities to successfully transition into adulthood were examined based on 10 domains: communication skills, academic skills, self-determination skills, interpersonal skills, community engagement skills, independent daily life skills, 
interdependent life skills, leisure and recreation skills, employment skills, skills for participating in post-secondary education programs and training.

[Table 1] shows the mean and standard deviation of each domain and questionnaire item, related to special education teachers' perceived importance of helping students to acquire transition skills required for a successful transition to adult life.

As shown in Table 1, the average difference between the level of perceived importance $(\mathrm{M}=4.20, \mathrm{SD}=.41)$ and the perception level of actual performance $(\mathrm{M}=3.60, \mathrm{SD}=.66)$ of teaching the 10 domains of transition skills to students with intellectual disabilities transitioning into adulthood was statistically significant $(\mathrm{t}=8.971)$ at the $.1 \%$ level. Special education teachers considered all 10 domains of transition skills to be important, but the degree they actually teach these domains in class was significantly lower than the level of their perceived importance. In view of these results, teachers are aware of the importance of their roles in teaching the transition skills required for a successful transition to adulthood, but they generally fail to put their thoughts into practice.

Table 1 Perceived importance and performance of teaching transition skills

\begin{tabular}{|c|c|c|c|c|}
\hline \multirow{5}{*}{ Independent living skills } & Importance & Performance & \multirow{2}{*}{$\mathrm{t}$} \\
\cline { 2 - 4 } & Communication skills & $\mathrm{M}(\mathrm{SD})$ & $\mathrm{M}(\mathrm{SD})$ & \\
\cline { 2 - 5 } & Academic skills & $3.52(0.57)$ & $3.85(0.76)$ & $8.128 * * *$ \\
\cline { 2 - 5 } & Self-determination skills & $4.39(0.52)$ & $3.73(0.78)$ & $8.218^{* * *}$ \\
\cline { 2 - 5 } & Interpersonal Skills & $4.09(0.57)$ & $3.52(0.84)$ & $6.517 * * *$ \\
\cline { 2 - 5 } & Commuinity engagement skills & $3.85(0.63)$ & $3.24(0.78)$ & $6.949 * * *$ \\
\cline { 2 - 5 } & Independent daily life skills & $4.58(0.42)$ & $4.00(0.80)$ & $7.468 * * *$ \\
\cline { 2 - 5 } & Interdependent life skills & $4.09(0.63)$ & $3.43(0.80)$ & $7.577 * * *$ \\
\cline { 2 - 5 } & Leisure and recreation skills & $4.13(0.66)$ & $3.57(0.82)$ & $6.154 * * *$ \\
\cline { 2 - 5 } & Employment skills & $4.53(0.43)$ & $3.93(0.75)$ & $8.024 * * *$ \\
\cline { 2 - 5 } & $\begin{array}{c}\text { Skills for participating in post- } \\
\text { secondary education programs and } \\
\text { training }\end{array}$ & $3.87(0.86)$ & $3.17(0.94)$ & $6.329 * * *$ \\
\hline Total & $4.20(0.41)$ & $3.60(0.66)$ & $8.971 * * *$ \\
\hline
\end{tabular}

\subsection{Transition skills that need to be taught for adolescents with intellectual disabilities}

[Table 2] shows the top 10 transition skills with the largest difference in the level of perceived importance and the perception level of actual performance. The greater the difference is, the more it is required to teach that skill at this point for the successful transition of students with intellectual disabilities.

Table 2. Transition skills that need to be taught more intensively

\begin{tabular}{|c|c|c|c|}
\hline Transition skills & Domain & Importance & Performance \\
\hline Using public transportation & $\begin{array}{c}\text { Independent daily life } \\
\text { skills }\end{array}$ & $4.75(0.50)$ & $3.93(1.03)$ \\
\hline $\begin{array}{c}\text { Learning problem solving skills in } \\
\text { social and practical situations }\end{array}$ & Self-determination skills & $4.52(0.60)$ & $3.77(0.89)$ \\
\hline Adapting to changing working & Employment skills & $4.41(0.69)$ & $3.63(0.92)$ \\
\hline
\end{tabular}




\begin{tabular}{|c|c|c|c|}
\hline conditions & & & \\
\hline $\begin{array}{c}\text { Listening skills (sign language, } \\
\text { spoken language) }\end{array}$ & Communication skills & $4.55(0.60)$ & $3.89(0.77)$ \\
\hline $\begin{array}{c}\text { Stick to work time without going } \\
\text { to work }\end{array}$ & Employment skills & $4.81(0.42)$ & $4.18(0.86)$ \\
\hline $\begin{array}{c}\text { Setting and achieving goals by } \\
\text { individuals }\end{array}$ & Self-determination skills & $4.13(0.70)$ & $3.41(0.86)$ \\
\hline $\begin{array}{c}\text { Employment in the Community } \\
\text { Expression skills (words, sign } \\
\text { language, AAC) }\end{array}$ & Independent daily life & $4.44(0.76)$ & $3.53(1.19)$ \\
\hline $\begin{array}{c}\text { Understand when someone else } \\
\text { needs support or help }\end{array}$ & Interdependent life skills & $4.26(0.62)$ & $3.61(0.84)$ \\
\hline $\begin{array}{c}\text { Speed, accuracy and precision of } \\
\text { the task }\end{array}$ & Employment skills & $4.58(0.58)$ & $3.90(0.96)$ \\
\hline
\end{tabular}

\subsection{Importance-Performance analysis of special education teacher on teaching transition skills}

[Table 3] and [Figure 1] shows Importance-Performance Analysis (IPA) of teaching 10 transition skills by using the mean difference between the perception of importance and performance of teachers. 10 transition skills are divided into 4 areas such as concentrate here, keep up the good work, low priority, possible overkill.

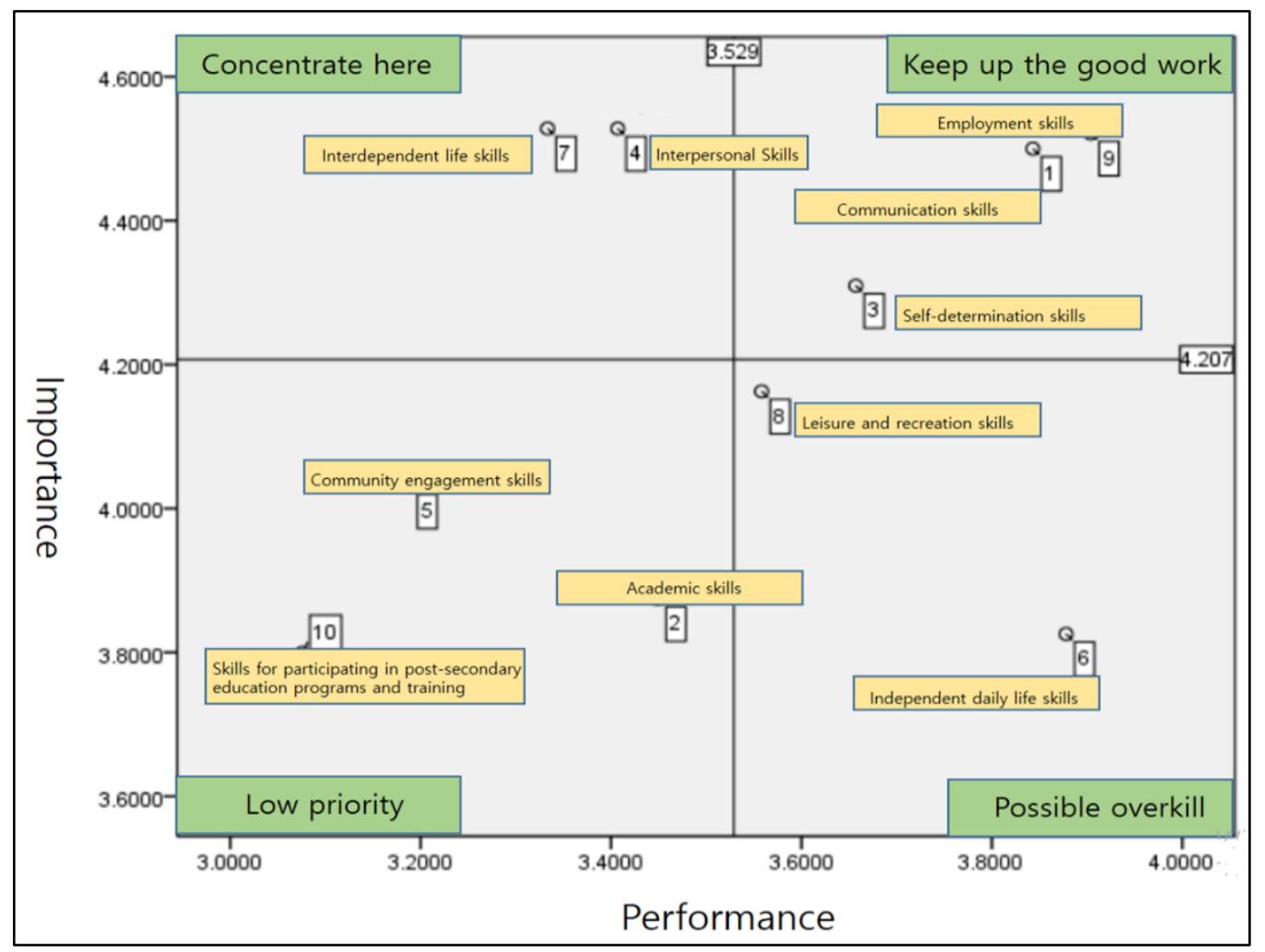

Figure 1. Importance-performance analysis 
Table 3. Importance-Performance analysis of teaching transition skills

\begin{tabular}{|c|c|}
\hline \multirow{2}{*}{ Domain } & Transition skills \\
\hline \multirow{3}{*}{ Concentrate here } & Interdependent life skills \\
\cline { 2 - 3 } Keep up the good work & Interpersonal Skills \\
\cline { 2 - 3 } & Communication skills \\
\cline { 2 - 3 } & Self-determination skills \\
\hline \multirow{2}{*}{ Low priority } & Employment skills \\
\cline { 2 - 3 } & Skills for participating in post-secondary education programs and \\
training
\end{tabular}

\section{Discussions and conclusion}

Special education teachers' perception level and perceived importance level regarding transition skills necessary for students with intellectual disabilities to effectively transition into adulthood were high, but the degree of their actual performance was lower than the perceived importance level. There was a significant difference between the perceived importance and actual performance. This could hinder the achievement of the goals of transition education to enhance their quality of life and to promote their social integration of students with intellectual disabilities. Therefore, it is necessary to establish the curriculum for transition education by developing and distributing transition education programs and teacher's guidebooks designed for different types and levels of intellectual disabilities or school levels, in order to motivate and facilitate teachers to help their students achieve social and financial independence [1][2].

Through importance-performance analysis, it is verified that special education teachers should focus on interdependent life skills, interpersonal skills, communication skills, selfdetermination skills, employment skills and not focusing on leisure and recreation skills, independent daily life skills.

\section{References}

[1] Park Y., "Analyzing the quality of secondary special education program for students with intellectual disabilities based on transition services program," A Mixed Method Study. Journal of Special Education \& Rehabilitation Science, vol.53, no.2, pp.69-90, (2014)

[2] Kraemer B. and Blacher J., Transition for young adults with severe mental retardation, "School preparation, parent expectations, and family involvement," Mental Retardation, vol.39, pp.422-435, (2001) 
[3] Park Y. and Park K., "The Significance of Family Involvement and Promoting Strategies in the Transition Process, A mixed method study," journal of special education: Theory and practice, vol.15, no.4, pp.439-460, (2014)

[4] Park Y., "Analyzing Dilemmas Faced by Special Education Teachers in Implementing Transition Services A Qualitative Analysis based on the Dilemmas Framework," Disability \& Employment, vol.23, no.4, pp.2957, (2013)

[5] Sitlington P. L., Clark G. M., and Kolstoe O. P., "Transition education and service for adolescents with disabilities (3rd ed)," Newton, MA, Allyn \& Bacon, (2000)

[6] Martilla J. A., and James J. C., "Importance-performance analysis," Journal of Marketing, vol.2, no.1, pp.7779, (1977)

[7] Nam Young-Hee, "A study on the injury prediction of LOS, discharge results, ICU," International Journal of IT-based Public Health Management, vol.6, no.2, pp.1-8, (2019) DOI:10.21742/IJIPHM.2019.6.2.01 